\title{
Effects of percentage occurrence of response members and its method of presentation on verbal discrimination learning and transfer*
}

\author{
ROBERT W. NEWBY \\ University of the Americas, Puebla, Mexico
}

\begin{abstract}
Each of 144 Ss learned two verbal discrimination (VD) lists for six trials. Two levels of percentage occurrence of response members $(100 \%$ or $50 \%)$ were combined factorially with two methods of presentation and three transfer paradigms $\left(\mathrm{C}_{1}-\mathrm{I}_{2}, \mathrm{C}_{2}-\mathrm{I}_{1}, \mathrm{C}_{2}-\mathrm{I}_{2}\right)$. In first-list learning, with one method of presentation in the $50 \% \mathrm{ORN} n . \therefore . \mathrm{b}$ : entire list was presented with only half the correct $(\mathrm{C})$ items designated on each study trial, while in the second metli: only half the list was presented with all $\mathrm{C}$ items underlined. There were no differences between the two methods in the $100 \%$ ORM condition. The results indicated that \% ORM was a significant variable in first-list learning, supporting the findings of Newby and Young (1972). No effect was found for method of presentation. Also, no real significant effect of these two variables was found in VD transfer. All results were interpreted in terms of the frequency theory of VD learning.
\end{abstract}

Newby and Young (1972) recently reported a significant effect of percentage occurrence of correct alternatives (analogous to percentage occurrence of response members, \% ORM) on verbal discrimination (VD) learning. Performance on the VD list was reduced significantly under the $50 \%$ ORM condition as compared to the $100 \%$ ORM condition. They attributed these results to a reduction of the rehearsal of the correct alternative response (RCR) as proposed by Ekstrand, Wallace, and Underwood (1966). This same effect was found by Gamboni, Gausted, and Wilson (1972).

In Newby and Young, part of this significant effect was apparently due to the method of presentation of the 50\% ORM condition. Briefly, the VD list was divided into two equal parts, and for one sublist the correct (C) items were underlined on odd-numbered study trials and not on even-numbered study trials, while for the second sublist the $\mathrm{C}$ items were underlined on even-numbered study trials and not on odd-numbered. It was found that Ss responded significantly more to those pairs in which the $\mathrm{C}$ items had been underlined on the previous study trial. Therefore, at least some part of the \% ORM effect was due to this presentation variable.

One problem concerning this effect, however, deals with the manner in which Ss were instructed to respond to the VD lists. In the Newby and Young study, Ss were not required to respond to each pair. Therefore, one purpose of the present study is to determine if this presentation effect occurs in a forced-choice situation.

This increasing and decreasing performance which paralleled the inclusion and omission of a line under the $\mathrm{C}$ item was explained in terms of the frequency theory of VD learning (Ekstrand, Wallace, \& Underwood,

\footnotetext{
*This research was done as part of the author's thesis which was submitted as partial fulfillment of the PhD degree at the University of Texas at Austin. The supervising professor was Robert K. Young.
}

1966). It was assumed that Ss attend primarily to those items in which the $\mathrm{C}$ item is underlined. If this was : case, equal frequency units would be added to $\mathrm{C}$ and incorrect (I) items in those pairs in which the $\mathrm{C}$ items were not underlined. This would make the discrimination for these pairs on the following test trial more difficult, which would thereby reduce performance on those pairs.

It is also possible that the Ss completely ignored those pairs in which the $\mathrm{C}$ items were not underlined, i.e., made no response to them at all. To test for this possibility, a second method of presenting a 50\% ORM list was compared to that used in the previous study. With this method, only those pairs in which the $\mathrm{C}$ item is underlined are presented to the $\mathrm{S}$ on study trials; $\therefore$ other half of the list is omitted entirely. This procecuir is al ternated over study trials.

If Ss are making some responses to the pairs in which the $\mathrm{C}$ items are not underlined, then performance with this second method will not follow that demonstrated by Newby and Young. If, however, the Ss do not attend to pairs in which the $\mathrm{C}$ item is not designated, then performance should be identical with both methods.

Also of interest is effect of \% ORM on VD transfer. Re:r. 1.: this area (Underwood, Jesse. \& Ekstrand, 04; Kausler \& Dean, 1967; Kausler, Fulkerson, \& Eschenbrenner, 1967; Kanak \& Dean, 1968; and King \& Levin, 1971) has demonstrated that positive transfer is obtained with the paradigm $\mathrm{C}_{1}-\mathrm{I}_{1}$, $\mathrm{C}_{1}-\mathrm{I}_{2}$, old $\mathrm{C}$ items and new $\mathrm{I}$ items (hereafter all paradigms will be referred to as second-list representation, i.e., $\mathrm{C}_{1}-\mathrm{I}_{2}$ ), and negative transfer with the paradigm $C_{2}-I_{1}$, new $C$ items and old $I$ items, both being compared to the control paradigm $\mathrm{C}_{2}-\mathrm{I}_{2}$, a new second list. The primary interest in this study is with the positive transfer paradigm $\mathrm{C}_{1}-\mathrm{I}_{2}$.

Newby and Young and Gamboni et al indicated that 


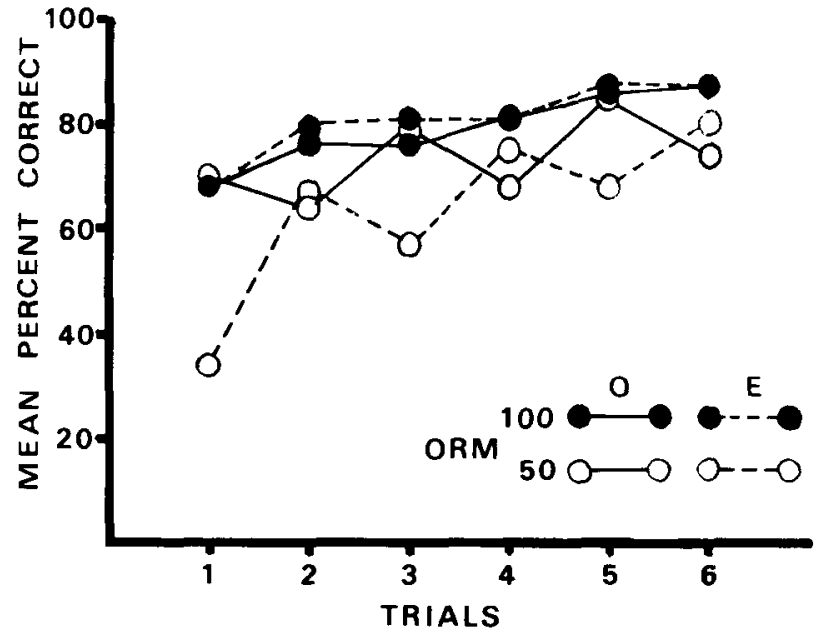

Fig. 1. Mean percent correct per trial for sublists on which correct response is underlined on odd trials ( $O$ sublist) and even trials ( $\mathrm{E}$ sublist).

reduction in \% ORM might have the effect of inhibiting $\mathrm{RCR}$. This would result in first-list $\mathrm{C}$ items in the $50 \%$ ORM condition having fewer frequency units than those used in the $100 \%$ ORM condition. This should in turn result in less positive transfer in the $C_{1}-I_{2}$ condition, because at the start of second-list learning there would not be such a great frequency difference in favor of the $\mathrm{C}$ items. Reduction in \% ORM should have no effect in the $C_{2}-I_{1}$ and $C_{2}-I_{2}$ conditions because the first-list $C$ items are not used in this second list.

\section{METHOD}

\section{Design}

Two levels of ORM were selected, $100 \%$ and $50 \%$, for first-list learning, and two methods of presentation were used. In both Methods 1 and 2 at the $100 \%$ ORM level, the $\mathrm{C}$ item was underlined on every study trial and all pairs were presented. With Method 1 at the 50\% ORM level, two sublists were randomly selected, one of which had eight pairs, the other having seven pairs. For Sublist $O$, the $C$ items were underlined on odd study trials and not underlined on even study trials, and for Sublist E, the $C$ items were underlined on even study trials and not on odd. With Method 2 at the 50\% ORM level, the same sublists were used. However, only Sublist $O$ was presented on odd study trials with the exclusion of Sublist $\mathbf{E}$. This procedure was reversed on even study trials. To equate for the differences in sublist length, the dependent variable was percentage correct per trial. Finally, paradigm was included as a variable. Three lists were employed as first lists in the paradigms $C_{1}-I_{2}, C_{2}-I_{1}$, and $C_{2}-I_{2}$, and all $S s$ learned the same second list. The \% ORM, method, and paradigm variables were combined factorially to yield a 2 by 2 by 3 design $(n=12$ per cell)

\section{Procedure}

The study-test method was used in the experiment in both lists. Six test trials on both VD tasks, each preceded by a study trial, were given. Two lists, A and B, consisting of 15 pairs of low-association nonsense syllables were selected from Archer (1960). The association value for the two lists ranged from 17 to 25 with a median value of 20 . A total of $60 \mathrm{CVCs}$ were used, 30 as $C$ items and 30 as $I$ items. List $A$ was used as the first list in the $C_{2}-I_{2}$ paradigm. The first list used in the $C_{1}-I_{2}$ condition (transfer) was made by taking the $\mathrm{C}$ items of List $\mathrm{B}$ and pairing them with the $I$ items of List $A$. The first list used in the $C_{2}-I_{1}$ transfer condition was made by taking the $C$ items of List $A$ and pairing them with the I items of List B. List B served as a common second list for all Ss. Formal similarity, both between and within lists, was minimized as much as possible by visual inspection.

Both lists were presented by means of a Kodak Carousel 650 projector with an attached automatic timer at a $3-\mathrm{sec}$ rate with a $12-\mathrm{sec}$ intertrial interval for both study and test trials. There was a 5-min interval between first- and second-list learning. A total of 144 Ss from introductory psychology classes were randomly assigned to each of the 12 experimental conditions. The Ss were instructed to write down the correct response for each pair presented in a six-page test booklet, even if they were required to guess. After each test trial, the page was turned and placed face down on the table in front of $S$. No $S$ had previously served in a learning experiment, and no $S$ was dropped from the experiment.

\section{RESULTS}

\section{First-List Learning}

The reduction of $\%$ ORM from $100 \%$ to $50 \%$ was found to have a significant effect on learning, $F(1,132)=$ $30.49, \mathrm{p}<.01$. This indicates that Ss' performance on the VD task was reduced by the reduction in \% ORM. Also, the list variable was found to be significant, $F(2,132)=4.32, p<.05$. This effect indicates differences in list difficulty, but since three different lists were used, these differences are not surprising. Also, it appeared that first-list differences were unrelated to second-list differences. The trial variable was found to be significant, $F(5,660)=51.87, p<.01$, which indicates that performance improved over trials. Finally, the odd vs even main effect was significant, $F(1,132)=16.78$, $p<.01$, indicating that performance was better on items presented on odd study trials than on those presented in even study trials. There was no significant main effect for method of \% ORM presentation.

The $\%$ ORM by $O$ vs $E$ interaction was found to be significant, $F(1,132)=28.46, p<.01$. The means of the $\mathrm{O}$ and $\mathrm{E}$ sublists were almost identical in the $100 \%$ ORM groups, while in the 50\% ORM groups performance was superior on the odd sublist. The Trials by 0 vs $E$ interaction was also significant, $F(5,660)=28.10$, $p<.01$. Orthogonal comparisons indicated that this interaction was due to a presentation vs nonpresentation effect, $F(1,660)=120.34, p<.01$. This meant that performance on the sublist presented in the preceding study trial was superior to that on the sublist which had not been presented. The List by Odd vs Even interaction was also significant, $F(2,132)=6.18, p<.01$, but this is thought to be due to the fact that different lists were used and therefore to be unrelated to second-list differences.

The \% ORM by Trials by $\mathrm{O}$ vs $\mathrm{E}$ interaction was found to be significant, $F(5,660)=29.35, p<.01$, and is presented in Fig. 1. Orthogonal comparisons indicate that a presentation vs nonpresentation effect occurred in 
the 50\% ORM condition, but not in the 100\% ORM condition, $F(1,660)=131.92, p<.01$. This replicates the findings of Newby and Young (1972). There were no differences between the two methods of \% ORM presentation, indicating that the Ss in the 50\% ORM conditions performed in the same manner regardless of method of \% ORM presentation.

Finally, there was a significant \% ORM by List by Trial by $\mathrm{O}$ vs $\mathrm{E}$ interaction, $\mathrm{F}(10,660)=1.85, \mathrm{p}<.05$, but due to the large number of $F$ comparisons this is probably a chance occurrence and of no behavioral significance.

\section{Second-List Learning}

Method of first-list \% ORM presentation had a significant effect on second-list learning, $F(1,132)=$ $4.36, p<.05$. This difference indicates that second-list performance was slightly better when Presentation Method 2 was used on List 1 as compared to Presentation Method 1. These data are presented in Table 1.

Also significant was the effect of first-list \% ORM on second-list learning, $F(1,132)=7.55, p<.01$. Second-list performance was better when the first list was learned under 100\% ORM as compared to $50 \%$ ORM. These data are also presented in Table 1.

The trial main effect was also found to be significant, $\mathrm{F}(5,660)=73.68, \mathrm{p}<.01$. This indicates that performance on the second list increased over trials.

The Paradigm by Trials interaction was found to be significant, $F(5,660)=3.88, p<.01$. This difference indicates that the performance over the three paradigms varied over trials. However, these results did not follow the usual VD transfer form of $\mathrm{C}_{1}-\mathrm{I}_{2}, \mathrm{C}_{2}-\mathrm{I}_{2}$, then $\mathrm{C}_{2}-\mathrm{I}_{1}$.

Additional comparisons were made on the data presented in Table 1. The group which learned the first list under 50\% ORM using Method 1 performed significantly worse than the other three groups, $F(1,132)$ $=363.75, \mathrm{p}<.01$. Also, those Ss who learned the first list under $50 \%$ ORM using Method 2 performed significantly worse than the two $100 \%$ ORM conditions, $F(1,132)=28.47, p<.01$. Finally, learning under $100 \%$ ORM Method 2 led to superior performance when compared to Method $1, F(1,132)=7.50, p<.01$. These comparisons indicate that performance on the second list varied as a function of both \% ORM and presentation method used on first list, but since the interaction between these two variables failed to reach significance, with $F(1,132)=1.48, p<.05$, their effects appear to be additive.

\section{DISCUSSION}

The analysis of first-isi learning essentially replicated those results by Newby and Young (1972). The significant \% ORM effect was found and thus indicated that a reduction in the RCR leads to poorer performance
Table 1

Mean Correct and Standard Deviations for the Percent ORM by Method of Presentation Interaction

\begin{tabular}{|c|c|c|c|c|}
\hline & & & \multicolumn{2}{|c|}{ Percent ORM } \\
\hline & & & 100 & 50 \\
\hline \multirow{2}{*}{$\begin{array}{l}\text { Method of } \\
\text { Presentation }\end{array}$} & İ & $\begin{array}{l}\text { Mean } \\
\text { SD }\end{array}$ & $\begin{array}{r}12.81 \\
2.31\end{array}$ & $\begin{array}{r}11.34 \\
2.84\end{array}$ \\
\hline & II & $\begin{array}{l}\text { Mean } \\
\text { SD }\end{array}$ & $\begin{array}{r}13.14 \\
2.06\end{array}$ & $\begin{array}{r}12.57 \\
2.43\end{array}$ \\
\hline
\end{tabular}

on the VD list. Also found was the increasing and decreasing performance on the sublists which paralleled their presentation and nonpresentation. Since this effect was found in the forced-choice procedure, the effect cannot simply be due to the fact that the Ss were not required to make a choice.

This phenomena was found with both methods of $\%$ ORM presentation, suggesting that Ss do not pay any attention to those items whose $\mathrm{C}$ items are not presented. This suggests a paradox with the theory which states that Ss should make representation and pronunciation responses to those items presented. If the Ss do not attend in any manner to pairs in which the $C$ items are not presented in Method 1, then these items should not collect frequency units, which in turn would not increase their difficulty on the next test trial. However, the results indicated that difficulty was increased on the following trial. The results seem, therefore, to indicate that the Ss both attend and do not attend to those pairs whose $\mathrm{C}$ items are not presented.

An explanation for these contradictory results may be found in the second-list comparisons made on the four groups defined by first-list \% ORM and presentation method. It will be recalled that second-list performance decreased the most when first-list learning was conducted under 50\% ORM using Method 1. Performance is slightly better when first-list learning was conducted under 50\% ORM using Presentation Method 2. It is possible that the Ss in Presentation Method 1, 50\% ORM condition, adapt the strategy during first-list learning of rehearsing the $\mathrm{C}$ items that are presented, ignoring the remaining pairs. They know that they need not attend to every pair and spend time during each study trial rehearsing $\mathrm{C}$ items. This would support the finding of Gamboni et al. The $S$ s in Presentation Method 2, 50\% ORM condition, rehearse each $\mathrm{C}$ item presented also, but they must attend to each pair presented even though not all pairs are presented on each study trial.

During second-list learning; the Ss continue to use their adopted strategy. Now, however, the Ss must attend to each pair presented on each study trial. This will be of no concern to the Ss of Presentation Method 2, 50\% ORM, because they are already accustomed to the task. However, the other Ss must now adopt a new strategy. It is now necessary to attend to each pair presented. Since they must adopt this second 
strategy, it would be expected that performance would be inhibited for this group. The differences between the two $100 \%$ ORM groups would seem to be due to differences in Ss, because the same lists were used and all $\mathrm{C}$ items were presented in each study trial.

This would explain the lack of difference between the two presentation methods in first-list learning. Presentation Method 1, 50\% ORM condition Ss were in fact paying no attention to the pairs in which the $\mathrm{C}$ items were not underlined. This would make their list the same as Presentation Method 2, 50\% ORM condition Ss. However, this is due to the adoption of different strategies on the part of the Ss.

This would also in part explain why second-list learning was superior following Presentation Method 2 compared to Method 1. The latter Ss were inhibited by the adoption of an incorrect strategy in the 50\% ORM group. This effect also seems to be due in part to differences in Ss in the two 100\% ORM conditions.

This present study was also designed to investigate the influence of \% ORM on VD transfer. It was predicted that by reducing \% ORM during first-list learning, performance with the $\mathrm{C}_{1}-\mathrm{I}_{2}$ paradigm would be reduced, because the number of frequency units accruing to the $\mathrm{C}$ items during first-list learning would be substantially reduced because of the reduction in number of RCRs made to the items. This effect would not occur with the paradigms $C_{2}-I_{1}$ and $C_{2}-I_{2}$. The results indicated that first-list learning under $50 \%$ ORM reduced performance on all paradigms in second-list learning. No differential effect over paradigms was found. This, too, seems to present some problem to frequency theory, but the results were probably due to the number of variables used in the study and of no real significance to the theory.

Also, the unusual transfer results, positive transfer with the paradigm $\mathrm{C}_{1} \cdot \mathrm{I}_{2}$ and negative transfer with the paradigm $\mathrm{C}_{2}-\mathrm{I}_{1}$ compared with the control paradigm $\mathrm{C}_{2}-\mathrm{I}_{2}$, were not found. However, this seems also to be due to the joint influence of the variables used in this study and should also not be taken as evidence against frequency theory.
In summary, the results supported the findings of Newby and Young (1972), indicating that the similar results are obtained when a forced-choice procedure is used. Although the predictions from frequency theory concerning the effects of \% ORM on VD transfer were not supported, this seems to be due to the fact that $\mathrm{Ss}$ abandon the use of frequency cues during one method of presentation in the 50\% ORM conditions. Further research is needed in this area before this explanation can be fully accepted.

\section{REFERENCES}

Archer, E. J. A re-evaluation of the meaningfulness of all possible CVC trigrams. Psychological Monographs, 1960, 74(No. 10).

Ekstrand, B. R., Wallace, W. P., \& Underwood, B. J. A frequency theory of verbal discrimination learning. Psychological Review, 1966, 73, 566-578.

Gamboni, W. R., Gausted, G. R., \& Wilson, B. E. Verbal discrimination learning as a function of percentage of reinforcing information (\% ORI) and varying presentation rates. Journal of Experimental Psychology, 1972, 93, 256-261.

Kanak, N. J., \& Dean, M. G. Transfer mechanisms in verbal discrimination learning. Journal of Experimental Psychology, $1969,79,300-307$.

Kausler, D. H., \& Dean, M. G. Direct and mediated transfer for right and wrong responses in verbal-discrimination learning. Journal of Verbal Learning \& Verbal Behavior, 1967, 6, 672-674.

Kausler, D. H., Fulkerson, F. E., \& Eschenbrenner, A. J., Jr. Unlearning of list 1 right items in verbal-discrimination transfer. Journal of Experimental Psychology, 1967, 75, 379-385.

King, M. E., \& Levin, I. P. Tests of frequency theory in verbal discrimination transfer with varying paradigms and List 1 trials. Psychonomic Science, 1971, 25, 226-228.

Newby, R. W., \& Young, R. K. Percentage of occurrences of correct response and implicit associative responses in verbal discrimination learning. Journal of Experimental Psychology, $1972,96,49-53$.

Underwood, B. J., Jesse, F., \& Ekstrand, B. K. Knowledge of rights and wrongs in verbal discrimination learning. Journal of Verbal Learning \& Verbal Behavior, 1964, 3, 183-186.

(Received for publication July 13, 1973; accepted August 17, 1973.) 